\title{
Discussion on Interference from L1 Culture to L2 Writing \&. Handling Suggestions
}

\author{
Ruxiang Ye \\ School of Foreign Languages, Anhui University of Science \&. Technology, \\ Dongshanzhong Road, 232001 Huainan, China. \\ rxye1975@163.com
}

\begin{abstract}
In view of high frequent occurrence of mistakes in China's college students' writing, the paper tries to analyze and discuss the types and reasons of these mistakes, identifying that most of the mistakes in college students' writing are caused by the interference of Chinese language, that is, negative transfer of L1 strategy on L2 writing, should not be ignored. Therefore, the author suggests that the development of cultural awareness and reasoning patterns of the target language and trying to reduce the interference of $\mathrm{L} 1$ culture on $\mathrm{L} 2$ writing will be the solution.
\end{abstract}

Keywords-English learning; first language culture; English writing; negative influence

\section{INTRODUCTION}

In recent years, there are growing researches on the correlation between the mother tongue and the L 2 writing, which have achieved considerable results. For example, ZHANG Wen-tao believes linguistic errors in China's college students' L2 writing arising from the interference of the structure of mother tongue are relatively conspicuous and its role of negative transfer could not be overlooked [1]. JIANG Pin points out that the negative transfer not only occurs in such aspects as grammar and vocabulary, but in culture and thinking modes [2]. Kaplan thinks our native culture thinking and knowledge will affect the organization in the second language learners' writing [3]. YAN Li-dong thinks that the researchers' interpretation and description on the errors not only strengthens the bidirectional study both as a theory and as a method, but also has an important inspiration on second language learning and foreign languages teaching [4]. However, the above researches for mistakes in Chinese students' English writing caused by native culture seem to offer no further presentation, or detailed analyses. This paper will discuss the specific types of mistakes interfered with by Chinese language conventions and the reasons in Chinese students' English writing and suggest appropriate strategies.

\section{TYPES OF MISTAKES}

Generally, in English learning there are four basic skills, listening, speaking, reading, and writing. The ability to write, the fourth level of these abilities, is the improvement of the other three abilities and it is understandable that English writing ability has always been the main item in various levels of the examination. For non-English majors in college, through two years of English learning, they should be grasping certain level of listening, reading, speaking and writing abilities, meeting the requirements of the college English teaching program. In reality, however, most students, including those who have passed CET-4 or CET-6, there are great disproportions in the development of various English language abilities. For instance, their abilities of reading and listening are usually better, while speaking and writing abilities are relatively weak. I launched a survey on the correction of English compositions of my students who come from Grade 2006 and Grade 2008, about 200, and found more than $73 \%$ of the mistakes in their compositions are related to the influence of our native culture (the rest mistakes belong to word spelling mistakes). Specifically, these culturally mistakes can be divided into several categories:

\section{A. Poor Diction}

This kind of mistakes was made largely because of the fact that English words and Chinese words do not belong to one-one corresponding. Usually a Chinese word can have a few English corresponding words. As an example, "Kan" in Chinese, can be translated into several words in English like "see", "look", "watch", "peer” and "glance”, etc. When Chinese students write compositions in English, owing to the influence of their mother tongue, they simply want to use the vocabulary of the translation from Chinese into English, not considering the deep semantic meaning of Chinese word and the limitation of English words in use. For example:

a) Their family can't give their education costs.

b) A part-time job can contribute to increase their experience.

\section{B. Chinese thinking pattern}

In China, most learners have at least ten years of Chinese-learning experience before they begin to learn English, and their thought patterns are inevitably influenced by their mother tongue, Chinese. Even learners who perform better in English learning can't avoid making mistakes in writing. After all, the time spent on English can never be parallel to that on Chinese. For students, there are only four or five hours exposed to English learning, which is absolutely insufficient. Therefore, "Chinglish" becomes a common phenomenon in Chinese students' English compositions. For example:

c) When he smiles, you will see that his teeth lost many. d) There are a lot of things changed in my home town since reforming and opening. 


\section{Mixture of sentence structure}

Strictly, such mistakes should be avoided; they are only grammatical mistakes, represented by double predicates, redundancy of sentence structure and variety of mixed patterns, etc. At first glance, these statements seemed to be understandable, especially for Chinese readers, but foreign readers will feel confused with the exact meaning. For instance:

e) There are have all kinds of sports we can take part in for the well-being of our bodies.

f) In spite of sports have its passive sides, for instance, it can cause injury, it can bring some bad manners, but sports still attract more and more people.

\section{Incoherence in statement}

For an internally coherent sentence, the following information introduced by its connecting part or concessive clue is usually consistent to the direction of the receiver's mental expectations, while coherence of a passage depends more on orderly connection between the sentences with semantic relations. There is numerous occurrence of incoherence with students' English writing. It is not a grammatical mistake, but consistence and combination. Even though there are no obvious mistakes in grammar with some students' English compositions, they still sound influent, incoherent and inconsistent when read, for example:

g) Nowadays, education is very important to a modern man. In my opinion, the concept of education has been broadened.

h ) In modern time, everyone wants to find a good job, a good job can earn much money, also make people happy.

\section{ANALYSIS ON THE CAUSES OF MISTAKES}

From the above existing problems in Chinese college students' English composition, it seems that the main reason for them lies in the following aspects:

First of all, influence of the mother-tongue culture. A language is the embodiment of the culture it belongs to, and acquisition of a language and understanding its culture are complementary and inseparable with each other. Learning a language equals learning its culture. Writing, as one of the purpose of attaining basic skills of the language output, must reflect the culture it represents. Chinese college students, who are affected deeply by the Chinese language, still cannot avoid the mode of thinking and reasoning process disturbed by Chinese language habits, and produce Chinese-style compositions that sometimes Chinese can understand while foreigners can not.

Secondly, Chinese college students lack understanding for the features of English writing. It is common for an English writer to put forward the point at the beginning and it is more straightforward and direct. There will be details or facts supporting after presentation of the viewpoint. In contrast, Chinese prefer indirect ways of expressing their ideas in writing. They seldom make the subject clear at the beginning, but reaffirm the viewpoints in many different ways, leaving readers enough room for reflection. In thinking pattern and organization of materials, English writing accents logical reasoning and clear organization and the finished article is always coherent and clear, thus an organic unity. While Chinese way of thinking pays little attention to the logical reasoning. In expression, English writing prefers deduction and places emphasis on originality and personalization. Therefore, the writer is encouraged to use his own words and unique way to present his points after the main idea made clear. Chinese writing tends to generalize and the main idea is often delayed till the end of the article. When writing, Chinese Students don't know how to use English to express and organize their ideas since they do not understand the differences between two languages, only to mechanically turn the Chinese ways of expression into English. No wonder that Chinese students' English writing to some foreign teachers is artificial and unnatural with logical confusion. [5]

Finally, students' misconception on English writing, most students hold a wrong idea that learning foreign languages is just learning the grammatical rules, remembering words, phrases and set terms, and writing is not as important as reading. This misconception largely influences students' attitudes towards learning tasks, and further affects the development of students' various abilities in English. Along with the deeply rooted tendency of emphasizing reading and ignoring writing in English teaching approach in China, there is much less time for writing training compared with other language skills, and some teachers even arrange writing activities totally at extracurricular period. Moreover, no enough attention is paid to writing in the college English tests at present. Instead, grammar and vocabulary are offered more attention to improve students' reading comprehension. Under this guideline, teachers and students all show no respect for writing, even though students are offered time for writing in class, they will not take it seriously, so it is difficult to achieve the aim of this activity.

\section{SUGgeStions TO THE PROBLEM}

In view of the common occurrence of errors caused by the interference of mother-tongue culture in college students' English composition in China, solutions to cope with the problem lie in the fact that we in the teaching of English writing should urge students to cultivate students' English cultural awareness, sense the differences between English and Chinese, avoid the interference of Chinese and think in English. Specifically, desirable are the following strategies in college English class.

A. Pay attention to the accumulation of the cultural knowledge related to the language we are learning.

As mentioned above, a language is medium of its 
culture, and learning a language is indispensable to acquiring its culture. Since we are learning English, our English compositions shall be natural and authentic, apprehensible to readers from English countries. In English class, as teachers, we should guide the students to realize the essential differences between two languages and the differences in thinking patterns between west people and Chinese people, and try to conceive and write in English reasoning. In addition, great attention should be paid to cultivation of English language and culture, and students should take notice of the differences between two languages in usage, function and context of vocabulary and phrases; teachers should strengthen students' English thinking and approach of expression in explaining grammar and presenting articles.

B. Make Use of students' reading materials as the guide to cultivate their ability to write.

Reading course, especially intensive reading, is the most important among the courses offered by Chinese universities. And this course always centers on articles, which is the focus of the college English learning. There is a need of detailed explanation and solid grasp of these articles with which the students are quite familiar. For example, when we explain these articles to the students, we may require our students to pay special attention to the diction like the word choice, usage of pronouns, adjectives and connectives within these articles, and the logical relations and linguistic ties between sentences, etc. Meanwhile, the articles are usually written by native speakers of English, and they are certainly natural and authentic in usage of language, reflecting the characteristics of contemporary English language. Frequent exposure to such cultivation, students will apply what they have acquired from the articles to his writing and gradually improve their English writing.

\section{Stress cultivation of writing process}

English writing teaching in China is result-oriented and the teacher assigns a writing task after roughly introducing certain type of writing skills, then compositions students completed independently were handed in to teachers. In judging, teachers accent the form of students' writing instead of the content, which is suitable for the education reality in China but has little help for students' writing. Process-oriented Writing can make up for the disadvantages of product-oriented writing. In process writing, students are not alone in a given topic and offer their products for correction, but write the preparation and plan to action steps, for example, discussion, debate, reading, thinking of ideas and listing. Many students work together to plan how to begin and how to organize a writing assignment. They conceive ideas, choose words and make sentences together, then write the first draft to submit to the teacher or the other students for feedback and revision. Accordingly the second draft can be achieved after attentive correction. The process of writing provides students with an opportunity to reflect, innovate, help and learn from each other. Consequently the students improve their English writing ability in practice.

\section{CONCLUSION}

Above all, it is quite common and severe that there are numerous errors in college students' English compositions in China. Because Chinese college students seldom touch natural and authentic English writing materials and they also have few opportunities to contact the native speakers of English. Chinese traditional English teaching methods emphasize grammar, vocabulary and reading skills. Hence, English writing ability has long been ignored and Chinese students' English writing ability is still weak. In their English compositions there are a great amount of mistakes interfered with by Chinese language. We need to take effective teaching methods and ensure that adequate teaching time to improve students' writing ability, but this is not enough. It is more important to help students develop a thorough sense of the nature of writing assignment, raising their awareness of English language and culture, to overcome the negative influence or negative transfer of Chinese language and culture in English writing.

\section{REFERENCES}

[1] W.T. Zhang, Analysis of interlingual and intralingual errors made by college students, Teaching English in China. Vol.26, pp.48, 2003.

[2] P. Jiang, Negative transfer in the aspects of language, culture and thinking pattern. Teaching English in China, Vol.20, pp.36, 2001.

[3] Kaplan, R.B. Cultural patterns in intercultural education. Language Learning, pp.16, 1966.

[4] L.D. Yan, Implication for second language pedagogy by analyzing errors in college students' writing, Teaching English in China, Vol.27, pp.27, 2004.

[5] Houston, A. learning writing through writing: the Chendu approach to teaching written composition, Teaching English in China, Vol.26, pp.100-110, 1994. 